University of Wollongong

Research Online

Faculty of Business - Papers (Archive)

Faculty of Business and Law

$1-1-2015$

Fitting the mould: the role of employer perceptions in immigrant recruitment decision-making

\author{
Shamika Almeida \\ University of Wollongong \\ Mario Fernando \\ University of Wollongong, mariof@uow.edu.au \\ Zeenobiyah Nadiyah Hannif \\ University of Technology Sydney, zeenie@uow.edu.au \\ Shyamali Dharmage \\ University of Melbourne, s.dharmage@unimelb.edu.au
}

Follow this and additional works at: https://ro.uow.edu.au/buspapers

Part of the Business Commons

Research Online is the open access institutional repository for the University of Wollongong. For further information contact the UOW Library: research-pubs@uow.edu.au 


\title{
Fitting the mould: the role of employer perceptions in immigrant recruitment decision-making
}

\begin{abstract}
Human capital theory presumes that skill-accredited immigrant professionals can access positions in the labour market to match their skills and qualifications. It implies that employers have little power to influence the labour market outcomes of immigrant professionals. Using social identity theory, we examine the influence of similarity effect in recruitment decision-making involving immigrant information technology (IT) professionals in New South Wales, Australia. We assess how decision makers $(\mathrm{N}=331)$ hiring IT professionals need to associate and identify with people that resemble themselves in some way more than those that do not, can influence their perception of the immigrant candidate's fit into their organisation. Particularly, we examine how the level of exposure to diversity, the decision maker's origin and the diversity of clientele can moderate the assessment of the candidate's fit to the organisation. We also assess how attire, name, accent and any overtly expressed religious affiliations influence employer perceptions. The findings indicate decision makers with lower levels of exposure to diversity or working in organisations with mostly Anglo clients tend to be more concerned of the fit regarding the Indians, Southeast Asians and the Chinese. They were also more likely to be negatively influenced by the non-Anglo personal attributes.
\end{abstract}

\section{Keywords}

mould, role, employer, perceptions, fitting, immigrant, making, recruitment, decision

\section{Disciplines \\ Business}

\section{Publication Details}

Almeida, S., Fernando, M., Hannif, Z. \& Dharmage, S. C. (2015). Fitting the mould: the role of employer perceptions in immigrant recruitment decision making. International Journal of Human Resource Management, 26 (22), 2811-2832. 


\title{
Fitting the mould:
}

The role of employer perceptions in immigrant recruitment decision making

\author{
Shamika Almeida, Ph.D. \\ Lecturer \\ Faculty of Business, University of Wollongong \\ shamika@uow.edu.au \\ Mario Fernando, Ph.D. \\ Associate Professor \\ Faculty of Business, University of Wollongong \\ mariof@uow.edu.au
}

Zeenobiyah Hannif, Ph.D.

Senior Lecturer

Management Discipline Group, UTS Business School

zeenie.hannif@uts.edu.au

Shyamali C Dharmage Ph. D.

Professor

School of Population Health

The University of Melbourne

s.dharmage@unimelb.edu.au 


\section{Abstract}

Human capital theory presumes that skill accredited immigrant professionals can gain access to positions in the labour market to match their skills and qualifications. Thereby, it implies that employers have little power to influence the labour market outcomes of immigrant professionals. Using social identity theory, we examine the influence of similarity effect in recruitment decision making involving immigrant professionals in the information technology (IT) industry in New South Wales, Australia. In a survey of decision makers $(\mathrm{N}=$ 331) hiring IT professionals, we assessed how the decision-maker's need to associate and identify with people that resemble themselves in some way more than those that do not, can influence their perception of the immigrant candidate's fit into their organisation. In particular, we examined how the level of exposure to diversity and international business practices, the decision maker's origin and the diversity of the clientele can moderate the assessment of the candidate's fit to the organisation. From the candidates' perspective, we examined how the attire, name, accent and any overtly expressed religious affiliations influence the employer perceptions. The findings indicate decisionmakers who had lower levels of exposure to diversity or working in organisations with mostly Anglo clients tended to be more concerned of the fit regarding the Indians, South East Asians and the Chinese. They were also more likely to be negatively influenced by the non-Anglo personal attributes during the recruitment decision making process. 


\section{Introduction}

There is a growing global trend where governments of many countries in the Organisation for Economic Co-operation and Development (OECD) are attempting to create policies to limit illegal and low skilled immigrants. These policies are created to encourage the immigration of highly skilled workers who are most likely to have a positive impact on their economies. As a result, tertiary educated immigrants in the OECD countries have increased by $70 \%$ in the past decade to reach 27 million in 2010/11, and one-fifth of them originated from India, China or the Philippines (United Nations- Department of Economic and Social Affairs, 2013).

Canada, Australia, New Zealand, United States, United Kingdom, France, Netherlands, Germany, Norway, Japan and Czech Republic are some of the OECD countries that have formalised policies and strategies in place to attract highly skilled migrants into their countries (Chaloff \& Lemaitre, 2009). Such migration programs aim to use skilled migration as one of the human capital strategies that can be operationalised to combat skill shortages (Cameron, 2011). These skill migration programs seem to be founded on the principles of human capital theory (HCT) (Smith, 2011), which assumes that skill-accredited professional migrants will gain access to the labour market and gain a position commensurate with their skills and qualification (Almeida et al, 2012). However, despite the rigorous assessment of migrants' qualifications and experiences, research suggests that skilled migrants from nonEnglish speaking backgrounds (NESBs) are less successful in finding employment that matches their skills than their English-speaking counterparts (Kostenko et al., 2012). Such 
underutilization is common in Western countries, including Britain (Qureshi et al., 2013), Canada (Somerville and Walsworth, 2009) and France (Ramboarison-Lalao et al., 2012).

This study examines the underutilisation of skilled migrants in New South Wales, Australia as an effect of social and group identity using social identity theory (SIT) (Ajzen, 1974; Devendorf and Highhouse, 2008). The paper explores the interrelationship of two factors: employers' exposure to diversity; and how it shapes their perception of a candidate's fit based on attire, name, accent and religious affiliations in recruitment decision-making in the context of the IT industry in New South Wales, Australia. Typically, research has noted a positive correlation between how generic interactions with a diverse group of individuals and intimate interactions such as dining with a diverse group of people resulted in better social ability, and higher rates of civic interests (Chang, Astin and Kim, 2004); how increased exposure to diversity can generate more tolerant racial attitudes (Pettigrew \& Tropp, 2006). and how the level of contact can help to reduce hostility toward migrants and promote more peaceful relations through increased inclusive treatment and willingness to embrace minority groups as full members of society (McLaren, 2003). However, there is very little research that has specifically examined how employer or decision-makers’ exposure to diversity can influence their decision making within a work context. We assess the employers' level of exposure to diversity and analyse its implications to recruitment decision making by using SIT as an alternative to HCT for explaining underutilisation of NESB skilled migrants. While HCT suggests that the power to gain employment lies within the control of the migrant, we argue instead that employers assert a significant power in determining the ability of migrant professionals to gain employment that maximizes their skill utilization. 
On the candidates' 'perception of fit', the body of research on immigrant recruitment show that several factors create a 'perception of fit' in the employer's mind about the suitability of a candidate. These factors can be dependent on non-Anglicised names (Leigh et al., 2009), heavy accents (Creese and Kambere, 2003), especially in relation to Asian accented immigrants (Hosoda and Stone-Romero, 2010), ethnic and religious reasons (McAllister and Moore, 1989) and cultural biases (Watson, 1996; Dunn, 2004; Wong, 2010). For example, Wong (2010, p. 191) notes that '...the recruiters examine the immigrant candidate’s expression, communication skills, confidence, grooming, appearance, accent, sense of humour and ability to make small talk to determine their 'fit' with the organisational work culture'.

The current study explores the candidate's attire, name, accent and religious affiliations within a recruitment decision-making in the context of the NSW IT industry in Australia.Our study contributes to the existing body of literature in two key ways. First, while earlier studies (e.g. Lippi-Green, 1997; Carlsson and Rooth, 2007; Hosoda and Stone-Romero, 2010; Ghumman et al., 2013; King and Ahmad, 2010; Oreopoulos, 2011) have focused on the difficulties faced by migrants in seeking employment, the focus has largely been on surfacelevel factors that do not fully capture why the human capital of migrants are undervalued. This paper provides a more in-depth insight into the factors that cause migrant skills to be undervalued, and in doing so, expands on the limited perspective offered by HCT. Second, by adopting an employer perspective through a SIT approach, this paper represents a departure from the bulk of the literature noted above which has opted largely for the employee/migrant perspective in understanding the migrant skill-underutilisation phenomenon. 


\section{Migrant skill underutilization and human capital theory}

The assumption of HCT is that job seekers have perfect information, are perfectly mobile, and that based on skills, the labour market treats all potential labour equally (Block, 1990; Evans and Kelley, 1991). The majority of the studies that use the human capital theoretical framework to explain migrant skill underutilization focus on issues relating to immigrants' qualifications, work experience and language skills. Let us consider each of these three issues individually.

Firstly on qualifications, HCT suggests that the job outcomes of migrants are positively related to their level of education and training (Markus, 2009). However, evidence suggests that skills are not perfectly transferable across countries and cultures (Kostenko, Harris, \& Zhao, 2012) . Similarly, research has shown that 'cartels' have been formed by some professional associations against overseas qualifications, particularly in the areas of nursing and medicine (Chapman and Iredale, 1993; Groutsis, 1998). This means that despite the level of qualification obtained, migrants who are educated in their home country are less likely to gain employment than locally qualified migrants (Qureshi et al., 2013). Further, although locally qualified migrants tend to have a greater chance of employment, their qualifications are still viewed less favourably than those of non-migrants (Parasnis et al., 2008).

Secondly, empirical evidence also suggests that even when qualifications are recognized as suitable for practice within a particular country, employers are reluctant to hire workers without host country work experience (Aydemir and Skuterud, 2004; Bauder and Cameron, 2002; Pio, 2005; Productivity Commission Research Report, 2006). Employers 
were identified as risk averse and 'simply [found] it easier to go for a domestically trained person’ (Chapman and Iredale, 1993, p. 380).

Thirdly, poor proficiency in the dominant language of the host country has also been associated with lower employment outcomes (Aure, 2012; Blythe et al., 2009; Hebbani and Colic-Peisker, 2012; Kostenko et al., 2012). For instance, Dustmann and Fabbri (2003) call attention to the English language skill deficits of immigrants and the tendency for these to result in lower employability and earnings. Consequently, immigrants from English-speaking backgrounds (ESBs) tend to have higher incomes than immigrants from non-English speaking backgrounds (NESBs), in part because of the inferior level of English language proficiency levels of the latter (Birrell et al., 2006).

In summary, although HCT emphasizes investment in education as imparting value to the future worker, it does not directly address the fact that this value must be harnessed in the labour market by employers in order for the human capital investment to be realized (Livingstone, 1999). The role of employers in influencing labour market outcomes of the immigrant professional is therefore not recognized within this theory (Almeida et al, 2012). Consequently, as Al Ariss et al (2012, p.92) note, immigrants' employment outcomes 'need to be understood as a relational construct that is at the interplay of individual and institutions and as a multi-layer and multi-faceted phenomenon' which identifies the need to understand the temporal and spatial context. In terms of this research, we contextualise and recognise the recruitment context and the employers or the decision-makers as key players that can influence the employment outcomes of migrants.

For instance, (Almeida et al, 2012) illustrates how an employer’s tolerance, stereotypes and comfort levels can result in the short listing and selection of persons who 
closely match the existing profiles of professionals within organisations. It may be that recruiters, HR professionals and heads of divisions responsible for recruitment decision making are influenced by the 'similar to me' effect, where they profile the potential candidate with a mirror image of themselves (Rudman, 1999). To understand this link between employers' preferences and their perception of a candidate's fit, the application of the similarity attraction paradigm could be helpful.

\section{The similarity attraction paradigm}

To understand migrant skill underutilization, researchers use the 'similarity attraction paradigm', 'homophily effect' or 'similarity effect', which are some of the most examined and robust effects in social psychology (Ajzen, 1974; Devendorf and Highhouse, 2008). The similarity effect posits that if a person has similarities with another, feelings of attraction and favour will be attributed to that person (Byrne, 1971; Montoya and Horton, 2012).

Studies examining the similarity effect are prolific, and meta-analyses generally agree that we associate feelings of 'liking', and identify better with people that resemble ourselves in some way than those that do not (Montoya and Horton, 2012; Singh and Teoh, 1999). Furthermore, feelings of liking have been shown to extend to the way we behave around similar people, and consequently affect our behaviours towards them (Roebken, 2010). A study by Caprara et al. (2007), examined how voters cast their votes in a mock election. Their study found that voting behaviour was related to how strongly the participants identified with or felt similar to the candidates. The similarity effect has been shown to affect interpersonal behaviour in a wide range of demographic and belief variables. These include generation, gender, occupation, ethnicity, culture, nationality, race, religion, political philosophy, dress, community type, interests, hobbies and knowledge (Ben-Ner et al., 2006). 
Various models have been developed in an attempt to support and explain the similarity attraction paradigm. Of these explanations, Byrnes’ effectance motive explanation, the information processing model and Social Identity Theory (SIT) appear to be the most popular (Ben-Ner et al., 2006; Byrne, 1971; Montoya and Horton, 2012). This paper specifically focuses on SIT to make sense of the issue of employer perceptions regarding the migrant fit into the Australian workplace.

\section{Social identity theory (SIT)}

One of the more well-known theories used to describe the similarity effect is SIT (Ashforth and Mael, 1989). This theory relies on observations that people tend to align themselves into social groups and categories (Baruch and Peiperil, 2000), including those relating to age, gender and ethnicity (Goldberg et al., 2010; Sacco et al., 2003). Evolutionary theorists suggest that this tendency towards group affiliation is an innate drive that most humans possess (Ben-Ner et al., 2006), and that it gives us physical security, and therefore provides a distinct evolutionary advantage towards survival and social fit.

By attributing importance to 'group', there is a tendency for people to distinguish between those in the same group as one, and those that are not. This is the in-group/out-group distinction (Goldberg, 2005). Individuals are more likely to identify with their in-group (those with whom they share similarities), while not identifying with their out-group (those to whom they are dissimilar). Healthy identification with one’s in-group promotes positive self-regard, which acts as a motivational factor. In comparison, over-identification with an in-group, leads to out-group hatred. In-group/out-group dynamics play a role in the development and maintenance of prejudices. For example, when an out-group is slurred, the collective identification with an in-group is triggered, which in turn leads to idealised comparisons of the in-group to the slurred out-group. This triggering of collective identity promotes 
depersonalisation of an out-group, leading to prejudice (Aviram, 2007). The strength of the similarity effect may depend heavily on the context of the situation in which individuals meet (Ben-Ner et al., 2006; Guest and Conway, 2002). For example, the similarity effect has shown to be the strongest in short interactions or when first meeting someone, but this effect is also shown to dissipate over the duration of a relationship (Montoya et al., 2008; Sacco et al., 2003). It is important that the context of the relationship is considered when looking for the similarity effect, because certain attributes may be more salient in different environments.

\section{Similarity effect in recruitment}

One environment in which the similarity effect may be particularly relevant is in the workforce, specifically with regard to workforce recruitment where decision makers must gain an impression of a job applicant within a limited time frame. Schneider (1987) proposes an attraction-selection-attrition framework in which similarity between employers and employees has consequences for the three stages of the employment relationship. In support of this meta-analysis, Sacco et al. (2003) state that perceived homogeneity makes communication easier, increases trust and makes behaviour more predictable; variables which are vital within a job interview context.

Although the attributes relating to ethnicity, religion and dress have all been identified as features implicit in the similarity effect and the way we regard ourselves and others (BenNer et al., 2006), the number of studies and the reliability of study findings conducted on the similarity effect in relation to job recruitment is relatively limited. In this paper, we aim to address this gap by examining the role of accent, attire, non-Anglo names and religion in the context of migrant recruitment specifically in relation to the IT employers in the state of NSW of Australia. 


\section{Accent}

Foreign accents have been shown to play a significant role in relation to employment-related decisions. In the context of job interviews in the United States, Hosoda and Stone-Romero (2010) found that applicants for high and low status jobs were treated differently, depending on their accent. For example, those with strong Japanese accents were less likely to be hired to low status jobs with high communication requirements.

Similarly, Deprez-Sims and Morris (2010) found that when two similarly qualified candidates applied for a job, those with a non-Anglo accent were less likely to be perceived as suitable for the job, and as a result, were less likely to be hired. The authors argue that this might be a result of rater-applicant similarity, in which similarity regarding demographic variables tends to inflate raters’ judgements about job competence and suitability. More recently, research conducted by Rakic et al. (2011) in Germany supports the notion that speakers with regional accents are perceived as lacking in competence or motivation or effort to speak the standard German language.

Evidence also suggests that job applicants with heavy non-Anglo accents are less likely to be recruited for jobs despite having the relevant qualifications in most Western countries that have a formal migration program. This may be more true for those jobs where communication is central to, and may also be influenced by the similarity effect between the job applicant and the decision maker, because accent is often used as a cue for group membership (Kim et al., 2011). Therefore, we aim to examine how accent can influence the recruitment decision making specifically in relation to the IT employers in the NSW region of Australia. The following hypothesis is proposed: 


\author{
Hypothesis 1: Favourable recruitment decisions concerning the perception of \\ fit of particular migrant ethnic candidates are negatively related to heavy \\ accents.
}

\title{
Attire
}

Kang et al. (2011) suggest that recruitment decision makers in human resources often hire in the best interest of the employer, which includes selecting candidates that make the company look good in terms of how its employers present themselves. This is a form of in-group/outgroup discrimination in which the in-group strives to keep a positive self-image via homophily, preferring those applicants that dress in line with the image of current employees. There is also support for the notion that dress may be used to enhance perceptions of trust, professionalism and responsibility (Trautner and Kwan, 2010). Consequently, it might be possible that applicants that dress in non-Western attire to job interviews may be treated unfavourably because they are part of an out-group.

There appears to be very little empirical evidence to support the notion that foreign attire affects recruitment bias based on similarity effect. One study conducted by Hensley (1981) shows that females at an airport were more likely to be given a coin to complete a telephone call if they dressed well, and were even more likely to be given money from those that were dressed similarly. However, the sample size for this study was very small, so results may be questionable. Overall, there has been little research on the issue of attire in both the context of the similarity effect and workplace recruitment. This area of study requires more attention, particularly given that foreign attire in the Western workplace is becoming more commonplace. Therefore, we aim to examine how non-Western attire can influence the recruitment decision making specifically in relation to the IT employers in the NSW region of Australia. The following hypothesis is proposed: 
Hypothesis 2: Favourable recruitment decisions concerning the perception of fit of particular migrant ethnic candidates are negatively related to having non-Western attire.

\section{Non-Anglo names}

A Swedish field experiment (Carlsson and Rooth, 2007) sent identical resumes to job openings with the only difference being the name of the applicant. They found that applicants with Arab/Muslim-sounding names were significantly less likely to be called for an interview than other applicants. The researchers suggest that recruiters were engaging in a form of implicit discrimination and stereotyping of those with Arabic names.

Similarly, a recent Canadian study by Oreopoulos (2011) found that Canadian-born individuals with English-sounding names were much more likely to receive a call back for a job interview after sending their resumes than foreign-born individuals, even if these individuals had foreign degrees from highly selective schools or similar previous work experience. When employers were asked why this was the case they responded that 'name was used as an interpretation of critical language skills’. People with foreign names were therefore avoided by decision makers in order to reduce the chance of 'bad hires'.

In Australia, an experiment conducted by Leigh et al. (2009) demonstrates how minorities fared better in the labour market if they Anglicized their names. Similarly, (Author) found that the name of the immigrant is a significant personal attribute that influences the employer evaluation of immigrant professionals in regional Australia during the recruitment evaluation phase. Therefore, we aim to examine how the non-Anglo name of a skilled migrant candidate can influence the recruitment decision making specifically in 
relation to the IT employers in the NSW region of Australia. The following hypothesis is proposed:

Hypothesis 3: Favourable recruitment decisions concerning the perception of fit of particular migrant ethnic candidates are negatively related to non-Anglo names.

\section{Religion}

Although there is a large amount literature regarding religious discrimination in the workplace (particularly in the US), there is very little to suggest that religious preference effects employee recruitment. Ghumman (2013) explains that hiring prejudices may exist towards religious groups because certain religious beliefs of applicants could pose challenges to the smooth functioning of the organisation. This is especially apparent in observable religious beliefs such as wearing a religious head-dress (Ball and Haque, 2003).

Employment decisions based on religious discrimination might also be supported by the similarity effect. Early research in the US by Marx and Spray (1972) suggests that mutually shared religious orientations provide interpersonal relationships with a bond that may be very important for certain individuals. Specifically, therapists in the mental health field seem to prefer patients who share their religious beliefs; however, whether or not this effect extends to the employer-employee relationship is uncertain. More recently, Ghumman et al. (2013) explained that organisations affiliated to particular religions may hire employees that display and share similar religious beliefs. Meta-reviews on the similarity effect describe religion as a significant moderator of liking when religion is common between two people (Ben-Ner et al., 2006). Finally, McPherson et al. (2001) describe that religious homophily is especially prevalent in societies with religious diversity, which is especially relevant in 
today's workforce, where ethnic and religious diversity is expanding. Although Australia is a secular society, we believe that Australian decision makers will be influenced by the overtly displayed religious affiliations of candidates during the recruitment process. Therefore, we aim to examine how the overtly expressed religious affiliation of a skilled migrant candidate can influence the recruitment decision making of IT employers in the NSW region of Australia. The following hypothesis is proposed:

Hypothesis 4: Favourable recruitment decisions concerning the perception of fit of particular migrant ethnic candidates are negatively related to overtly displayed religious affiliations.

Based on the above hypothesized relationships, the following figure representing the variables can be presented:

$<$ insert Figure 1 near here $>$

\section{Methodology}

\section{Context}

Australia has come to rely heavily upon the skills of migrants in several key industries; information, communication and technology (ICT) being one of those (Department of Education Employment and Workplace Relations (DEEWR), 2012). Australia’s permanent residence migration program has been designed as a gateway to gap these much needed skills in Australia. This permanent skill migration program consists of two streams. These are the Family Stream, which allows for the migration of immediate family members of current residents, and the Skill Stream, which grants visas based on how well an individual's skills, entrepreneurship and capabilities are able to benefit the Australian economy (DIC, 2012). 
The 2011-12 for the Australian migration program was one of the largest to date, with an additional 16,300 places added to the program in 2011-12 (DIC, 2013). The Skill Stream made up the majority of the migration program in 2011-12, with 125,755 places filled compared to 58,604 places in the Family Stream (DIC, 2013). In terms of ICT skilled migrants, 17 percent of total permanent arrivals in Australia were computer professionals premigration and 12 percent were noted as working in this field, post-migration (Hawthorne, 2011).

The top three source countries for the 2011-12 Australian migration program were India (29,018 places), the People’s Republic of China (25,509 places) and the United Kingdom (25,274). This was followed by the Philippines (12,933 places) and South Africa (7,640 places), with other countries making up the remaining 84,624 visas (DIC, 2012). Alternatively, temporary migration is possible through the temporary residents program, which selects migrants for specific purposes based on their potential contribution to Australia. The majority of skilled temporary residents migrate on the Temporary Business (Long Stay) (subclass 457) visa and is now forming a larger part of the Australian temporary resident program than in previous years. However, this paper will specifically focus on the permanent skill migrants.

\section{Sample}

An email inviting participation in an online survey questionnaire was sent out selectively to 6500 HR professionals and recruitment decision makers from various organisations located in the state of New South Wales, Australia. Of the emails, approximately 20-25\% returned due to bad email addresses or change of jobs. There was another $10 \%$ returned emails noting that the recipient is on leave. The invitees were accessed through the client database of Change 
Recruitment ${ }^{1}$, a Sydney-based HR services company specializing in the recruitment of IT personnel. Consequently, it is a selective sample that covered one occupational group in one specific region in Australia. The questionnaire was completed by 428 respondents. Prior to analysis, 75 respondents were excluded because their responses had significant missing data (> 75\%) beyond basic demographic questions. A further 22 responses had missing data, typically in the dependent variable, perception of fit (POF). To address this issue, list-wise comparisons were applied to all analyses with missing data so that respondents with missing data were excluded from the relevant analysis. The use of list-wise deletion of missing data is appropriate when the loss of data is small and when the sample size is large (Marsh, 1998). As a failsafe measure, tests were carried out between respondents with and without missing data to check whether the two groups differed significantly on any demographic measure. They were found to be statistically similar on all demographic measures, thus it was deemed justified that these responses with missing data were excluded from the analyses. Thus a total of 97 responses were deleted due to missing data resulting in a final total of 331 useable surveys. The low response rate can be attributed to several reasons.

First, the time at which the emails were sent out could have limited the response rate. The emails were sent out during the last week of November and early weeks of December. Some of the executives could have been on leave until after mid-January due to the Australia Day holiday celebrations. It is possible that recipients when clearing their large unattended inboxes after their return to work deleted emails requesting their participation in the survey.

\footnotetext{
${ }^{1}$ Name changed to conceal identity.
} 
Second, it is well-documented that the respondents' willingness to complete a survey depends on the topic of the study especially when the recipients are members of a senior management team (Geer et al, 2000). Some questions in the survey required responses to sensitive and potentially controversial topics. It is likely that those who chose to not respond to the survey considered the research too sensitive and the respondents may not have wanted to disclose personal and organisational biases or attitudes towards particular groups. This could be due to factors such as the confidentiality of information or concerns regarding how the ethical behaviour required by organisational rules and culture may be perceived by members of the public. Several email recipients contacted the researchers via email indicating that they do not want to proceed with the survey due to the above mentioned reasons.

Third, the survey targeted senior managers who are responsible for recruitment policymaking and decisions. Reasons such as their stressful work role, as well as company rules and policies can negatively influence senior managers' likelihood of responding to the survey (Geer et al, 2000) which then reduces the response rate of senior managers in comparison to the response rate of the consumer populations (Baruch and Holtom, 2008; Geer et al, 2000) and student populations.

The demographic details of the sample are shown in Table 1.

$<$ insert Table 1 near here $>$

It is also important to note that most of the respondents who participated in the survey could have been either first, second or third generation immigrants or had some form of affiliation with minority ethnic groups. This point was indicative from the positive feedback received by researchers from several survey participants. The participants' level of empathy to the issues concerning the ethnic minority groups or their level of familiarity with issues concerning the topic of the survey could have prompted this positive feedback. One of the 
questions in the survey was to indicate the ability to participate in an interview for a followup qualitative study. To date, 25 executives have indicated their willingness to participate in a follow up interview. Of the 25 people, 10 executives could be classified as Anglo Australian, others were first and second generation Anglo and ethnic minority immigrants. Many of the Anglo Australians who participated in the interviews had either worked in other countries or had close relationships (i.e., spouse or close friend) with persons who originated from a minority ethnic group.

All participants in the survey were promised anonymity. No personal details or the organisational name were requested. However, an email address was requested if the participant was willing to be interviewed at a later date.

\section{The questionnaire}

The questionnaire included the measure of the variables of accent, attire, non-Anglo names, religious affiliation and POF. The survey items were developed from a literature review and field interviews of HR professionals (see Author). These survey items were then reviewed by three independent HR managers and two senior HR professors with over 20 years of experience in HR research.

Recruitment decision makers’ POF of particular ethnic groups was measured through a four-point Likert scale (1 being ‘strongly disagree’ and 4 ‘strongly agree’). POF was measured using 13 items related to four domains: immigrant candidate’s qualifications, work experience, communication skills and personal attributes. The measure had good reliability, as determined by the Cronbach alpha statistic of internal consistency $(\alpha=0.84)$.

Respondents were requested to read various statements on (a) accent (for example, accent could play a significant role in positive evaluations), (b) attire (for example, 
candidates not appropriately attired in Western style could have difficulty in gaining entry into the organisation), (c) non-Anglo names (for example, non-Anglo names can have an unfavourable influence during the short-listing phase) and (d) religion (for example, overtly displayed religious affiliations of candidates could unfavourably influence the recruitment of such individuals). Respondents were then required to indicate the extent of agreement or disagreement through a four-point Likert scale (1 being ‘strongly disagree’ and 4 ‘strongly agree'). Control variables consisted of the items age, gender, recruitment decision maker's exposure to diverse cultures, ethnic origin, seniority of decision maker, organisational size and diversity of clientele.

\section{Data analysis}

Several tests were used to analyse the data between various subgroups. Initially, t-tests were used to examine variables between groups. Examination of skewness and QQ plots were used as tests for normality, and Likert data was initially treated as interval. Levene tests were used to test equal variance between groups and the appropriate t-test results were then interpreted.

However, the four-point Likert scale data may be treated as ordinal rather than interval. As such, in addition to the above tests Mann-Whitney U (Wilcoxon Rank Sum) tests were also conducted on the same subgroups against the same set of dependent variables. The Mann-Whitney $\mathrm{U}$ test is a non-parametric test for assessing the identical probability distributions of two populations (Kvanli et al., 2000). It was used to identify the similarities and differences between groups such as the mainly Australian white clientele compared to the more diverse clientele. Any significant statistical differences suggest that the dependent variable differed significantly as a function of group. Both tests (the t-test and the Wilcoxon rank-sum) revealed almost identical significant differences, with the only differences being the degree of significance. When tests differed in significance, Wilcoxon rank-sum results 
were interpreted, because they provide a more conservative measure of between-group differences.

In order to further ascertain whether greater cultural awareness might result in a tendency to disagree with the POF items listed in Table 2, Spearman's correlational analyses were conducted. Spearman's correlations were used rather than Pearson’s, because Likert data with fewer than five points is better treated as ordinal rather than interval. Accordingly, linear/multiple regression analyses were not conducted to avoid violations of basic assumptions of normality and heteroskedasticity.

Independent variables included gender, generation, ethnicity of clientele, cultural understanding of decision makers and ethnicity of senior management. An alpha level set at $\alpha$ $=0.05$ was used as a measure of significance for all statistical tests.

Overall, crosstabs support the original results of the t-tests; however, logical regression models do not. Rather, they support the notion that increased agreement with these statements means that the respondent is more likely to have a high cultural understanding. The variance explained by these models is very small, indicating small effect sizes.

\section{Results}

The means and standard deviations of the responses to the key variables are provided in Table 2. Table 3 describes significant differences between groups and relevant Wilcoxon signed rank test results.

\footnotetext{
$<$ insert Table 2 near here $>$

$<$ insert Table 3 near here $>$
} 
With regard to the accent of immigrant candidates, the findings support our first hypothesis: that recruitment decision making concerning the perception of fit of particular ethnic groups was negatively related to heavy accents. This effect was found between decision makers from white Australian backgrounds against those that were accepting of or originated from an immigrant background, with the former group having a significantly greater tendency to agree that a candidate's accent could play a significant role in their positive evaluation.

Regarding non-Western attire of immigrant candidates, the findings support our second hypothesis: recruitment decision making concerning the perception of fit of particular ethnic groups was negatively related to non-Western attire. Candidates not appropriately attired in a Western style applying for positions were thought to have a difficult passage to entry. When respondents were divided into various subgroups including the ethnicity of decision makers, ethnicity of clientele and cultural understanding of decision makers, organisations with Anglo-Austrian clientele, decision makers with low cultural understanding or from a white Australian background were significantly more likely to agree with this statement, as described in Table 2.

Our third hypothesis was also supported regarding candidates’ non-Anglo names: recruitment decision making concerning the perception of fit of particular ethnic groups was negatively related to non-Anglo names. Those companies with mainly white Australian clients agreed significantly more (than those companies with ethnically diverse clientele) that a non-Anglo, ethnic-sounding name can have an unfavourable influence during the short-listing phase (Table 2). These types of clients also perceived that it is important for candidates to maintain eye contact during interviews and demonstrate their knowledge of the 
most popular Australian sports to project a better fit with the culture $(\mathrm{W}=23766.59, \mathrm{p}=$ $0.000)$.

Candidates from Indian, Chinese and South East Asian backgrounds were most likely to be negatively affected during the short-listing phase. The findings show that white Australian decision makers typically had concerns about fit regarding those of Indian, South East Asian, and Chinese backgrounds in comparison to ethnically diverse decision makers. The results, however, were not significant for Lebanese or Middle Eastern ethnicities. Significant results are presented in Table 4.

$<$ insert Table 4 here $>$

In terms of the religious affiliation of candidates, the findings support Hypothesis 4: recruitment decision making concerning the perception of fit of particular ethnic groups was negatively related to religious affiliations. When cultural understanding was low (compared to high) this group of respondents were significantly more likely to agree with the statement 'overtly displayed religious affiliations of candidates could unfavourably influence the recruitment of such individuals'.

Data were also analysed in relation to demographic variables. For example, for entrylevel IT positions, personal attributes and work experience were favoured significantly over qualifications, as determined by a Friedman's between group analysis $x^{2}(2, N=301)=62.80$, $\mathrm{p}=.00$. Similarly for middle and senior management IT positions, work experience was favoured over personal attributes, which in turn were favoured over qualifications $x^{2}(2, N=$ $301)=203.01, x^{2}(2, N=301)=62.80$ respectively. Furthermore, large organisations (with more than 100 employees) were more significantly likely to use tick-box approaches during their recruitment process in comparison to smaller organisations $(U=5798, Z=-2.82, p=$ 
.005). Small organisations were more likely to use word-of-mouth referrals than large organisations as determined by a crosstabs analysis $(\mathrm{R}=26.24, \mathrm{df}=3, \mathrm{p}=.00)$. There were no significant differences between large and small organisations in their perceptions of fit.

Support for all of the hypotheses means that during the short-listing process, accent, non-Western attire, non-Anglo names and the religious affiliation attributes of candidates negatively influenced the recruitment and short listing of particular ethnic groups. Specifically, this was most relevant for groups that dealt with predominantly Anglo clients or when decision makers in an organisation were judged by respondents as having limited cultural understanding or exposure.

\section{Discussion}

This study examined the attributes religion, attire, accent and non-Anglo names in the context of workforce recruitment in the IT industry. Drawing on the limited number of studies that have focused on these individual attributes during the recruitment phase, we hypothesized that recruitment decision making concerning the perception of fit of particular migrant ethnic candidates was negatively related to heavy accents, non-Western attire, religious affiliations and non-Anglo names. Subsequent analysis of the survey data confirmed these hypotheses. In other words, heavy accents, non-Western attire, overtly displayed religious affiliations and non-Anglo names can have an unfavourable influence on decision makers during the shortlisting process. As determined in earlier research (see Lippi-Green, 1997; Carlsson and Rooth, 2007; Hosoda and Stone-Romero, 2010; Ghumman et al., 2013; King and Ahmad, 2010; Oreopoulos, 2011), these unfavourable influences in turn may explain the poorer employment outcomes for those candidates exhibiting such attributes. 
Support for the similarity effect was also ascertained through this research by analysing responses on the basis of recruitment decision makers' exposure to diverse cultures and decision makers' ethnic origins. The findings suggest that decision makers from white Australian backgrounds (compared to those from an immigrant background) and those with low cultural understanding/exposure were more likely to agree that a heavy accent, nonWestern attire, ethnic-sounding name or religious affiliation could unfavourably influence the recruitment of immigrant candidates exhibiting these attributes. As such, the background of the decision maker and their exposure to cultural diversity plays a key part in how immigrant professionals are evaluated. White Australian decision makers were also more likely (than ethnically diverse decision makers) to question the 'culture fit' of candidates from Indian, Chinese and South East Asian background (Table 4). These ethnic groups were therefore the most likely to be negatively affected during the short-listing phase, despite being in the top four source countries for the 2011-12 Australian migration program.

To further explore this finding, the in-group/out-group dichotomy that underlies SIT could be used. SIT suggests humans naturally align themselves into social groups and categories, including those relating to age, gender and ethnicity (Goldberg et al., 2010; Sacco et al., 2003), and are therefore more likely to identify with their in-group (those with whom they share similarities) than with their out-group (those from whom they are dissimilar) (Aviram, 2007). Ben-Ner et al. (2006) suggest that in addition to increased attraction to those in the in-group, people are also willing to share, give and communicate more with those who resemble and share identity. The perceptual biases that exist against migrants to Australia may provide further insight.

Interestingly, the four investigated attributes were less likely to negatively influence evaluations of skilled immigrants by those decision makers who had greater exposure to 
cultural diversity. This suggests that candidate evaluations are influenced not only by their 'foreignness', but by the exposure that the decision maker has had to cultural diversity. These findings also support Binder et al.’s (2009) suggestion that contact between minority and majority groups acts to reduce prejudice within majority group members (Binder et al., 2009). Conversely, prejudice acts to reduce contact (Binder et al., 2009), suggesting that employers who hold prejudicial beliefs against visible migrants are likely to avoid contact with them, preventing any opportunity for such beliefs to be reduced.

Those organisations with mainly white Australia clientele also tended to agree that a non-Anglo name, lack of eye contact, non-Anglo attire and lack of understanding of popular sports would lead to more unfavourable evaluations of migrant candidates. Those with Anglo clients also tended to be more concerned regarding the culture fit of those from India, South East Asia and China. In these instances, it appears that factors beyond the demographics of the decision makers play a part in the evaluation of immigrant candidates. Consequently, even where decision makers have had cultural exposure, the demographics of the clientele may lead immigrant candidates to be adversely affected during the short-listing phase.

These results provide additional evidence of the inadequacy of the HCT in effectively explaining the skill underutilization phenomenon in Australia. While HCT posits that the job outcomes of migrants are positively associated with their education and training (Markus, 2009), even where candidates are adequately qualified for positions, the findings from this study suggests that migrants’ qualifications do not carry as much weight in the short-listing phase as their personal attributes or work experience. Wagner and Childs (2006) suggest that local work experience is perceived by employers as evidence of the candidate's ability to integrate socially and culturally, and is thus considered a key determinant in judging a candidate's potential fit within the organisation. Furthermore, as determined by Hebbani and 
Colic-Peisker (2012), the performance of skilled migrants in interviews can be negatively affected by cultural differences, with differences in the use of eye contact, gestures and body language being related to poorer outcomes. Knowledge of popular sports can also be considered an indicator of culture fit, with those candidates exhibiting this attribute more likely to be judged favourably.

Thus, contrary to the HCT, these findings suggest that holding a relevant qualification, even one that is recognized as part of the national skilled migrant visa program, is no guarantee of employment at skill-accredited levels. Local work experience, personal attributes (particularly those that are more Anglo in nature) and overall cultural fit are considered by decision makers to be of much greater importance. This provides support for the thesis that the transferability of skills is affected by the cultural and social backgrounds of migrants (see Kostenko et al., 2012). While at the macro level similarities in labour market structure, institutional settings and specific skills are necessary to facilitate the effective transfer of human capital (Kostenko et al., 2012), at the micro-level, the similarity effect is also an important mediator in this process.

\section{Theoretical and practical contributions}

While previous studies have explored the challenges experienced by migrants in finding employment (e.g. Ball and Haque, 2003; Carlsson and Rooth, 2007; Oreopoulos, 2011; Ghumman, 2013), these studies have focussed on surface-level factors, and have not examined the relationship between migrant job-seeker attributes and employer attributes. By adopting an employer perspective using SIT, and examining a broader range of job seekerattributes, in this paper we aimed to develop a deeper understanding of the migrant skill 
underutilisation phenomenon. In addition, by undertaking this study, the limitations of HCT in explaining migrant skill underutilisation is further emphasised.

The assumption of the HCT is that job seekers have perfect information and are perfectly mobile, and that the labour market treats all potential labour equally based on their skills (Block, 1990; Evans \& Kelley, 1991). While this theory emphasises the importance of investment in education in imparting value to the future worker, it does not directly address the fact that this value must be harnessed in the labour market by employers in order for the human capital invested to be realised (Livingstone, 1999). Here, the concept of symbolic capital, defined by Al Ariss and Syed (2011, p. 295) as 'the reflected power that gives individuals the ability to accumulate and deploy social, cultural and economic capital' is particularly relevant. As O“zbilgin and Tatli (2005) explain, the 'harnessing' of talent is contingent on the individual and collective perceptions surrounding the symbolic value of the capital.

Nevertheless, within the realm of HCT, the role of employers in influencing labour market outcomes of the immigrant professional is not recognised. The newly arrived immigrant is deemed responsible for socially integrating and finding employment that aligns with their skill level. When these new immigrants are unable to gain employment that effectively utilises their skills, this too is seen as a failure to live up to their responsibility (Becker, 1971; Welch, 1975).

The literature from the social psychology field provides an alternative explanation for the migrant skill underutilization phenomenon by focusing on the perceptions and behaviours of decision makers during the recruitment process. Herein lies one of the key theoretical contributions of this paper. The similarity effect paradigm in particular offers insight into 
factors that influence decision makers' evaluations of immigrant candidates during the shortlisting phase. Evidence for the existence of a similarity effect is well established in the social psychology literature, with meta-analyses consistently confirming that demographic similarities between two people will result in a greater chance of reciprocal liking and interpersonal attraction (Byrne, 1971; Montoya and Horton, 2012). While there are several models that support this theory, there is a surprising paucity of research on how the similarity effect influences the job recruitment process. Nevertheless, the research that has been conducted (for example, Harrisons et al., 1998; Ghumman et al., 2013) suggests that decision makers in the recruitment phase rely on salient candidate attributes such as candidate accent, skin colour and dress to construct their judgements about candidate suitability and fit. Candidates with attributes that are similar to those of the decision maker(s) or current employees are likely to be judged more favourably than those that do not possess similar attributes.

In view of the above, the findings of this study have three main theoretical implications. First, we have added to the literature on recruitment decision making of skilled immigrants by demonstrating that, in addition to HCT, personal factors such as applicant's religion, accent, attire and non-Anglo names have an important bearing on recruitment decision making outcomes. Earlier studies have focused only on job seeker factors and in an isolated manner, and have not explored the interaction between job seeker and decisionmaker attributes. Second, we introduced a social psychology perspective to explaining why these four factors could impact on recruitment decision making outcomes. Adopting an employer perspective is a novel approach as far as the existing body of literature is concerned, and is helpful in theorising about the effects of skilled immigrant recruitment decision making beyond the HCT framework. Through this approach, we have offered a 
theoretical rationale and underlying mechanism that might explain why certain immigrant recruitment decision making outcomes may not reflect the qualification standards and work experience levels of skilled immigrant applicants. Third, we demonstrate that factors beyond the demographics of the decision maker, that is, decision makers' cultural exposure and the diversity of the client base can play a vital part in the evaluation outcomes of skilled immigrant candidates.

In terms of practical implications, our results provide support for the suggestion that organisations should develop intervention programs to inculcate among recruitment decision makers better awareness to recognise how an immigrant applicant's personal attributes such as religion, accent, non-Anglo names and attire can affect their decision outcome. These could take the form of building awareness in decision makers through training seminars showcasing skilled immigrant applicants’ recruitment experiences. Furthermore, mechanisms to counter the similarity effect on immigrant recruitment decision making stemming from the recruitment decision makers' exposure to diverse cultures and the diversity of clientele should be formulated and implemented. For instance, as opposed to individual decision making, organisations could promote group decision making whereby decision outcomes are likely to be based on greater diversity in ethnic and cultural experiences.

\section{Limitations and future research}

Despite the fact that the research propositions and findings from this research make several contributions, future researchers need to be aware of the key limitations of this study. The first is the sample size and context of the research. This quantitative

study was based on employers who recruit IT professionals in New South Wales, Australia. Consequently, it is a selective sample that covered one occupational group in a specific 
region in Australia. It is recommended that researchers extend this research to other occupational groups (such as nursing and engineering) other geographical areas, using a combination of a quantitative and qualitative approaches.

The second key limitation is that this research ignored the gender perspective. Generally, the IT occupation tends to have more males than females. For example, according to the Australian Bureau of Statistics (2001), 78\% of the computer professionals in Australia were males. Researchers could consider adopting a gender sensitive approach to examining whether the recruitment and selection behaviour of employers varies according to the gender of the participating decision maker and the gender of the immigrant applicant.

It may also be useful to extend this research to examine how the employer's level of exposure to diversity and international business practices, their origin and the diversity of the clientele can moderate their assessment of migrants’ career development and progression after recruitment to the organisation. Such an examination may give researchers some insight into the long-term skill use of immigrant professionals. This may involve a longitudinal study on the employers and their human resource management of skilled immigrant professionals across some of the key occupational groups, industries and different organisational sizes. Such an in-depth longitudinal study can support immigration policy in Australia to keep abreast of the changing needs of the employers and thus remain competitive globally. 


\section{References}

Ajzen, I. (1974), ‘Effects of information on interpersonal attraction: similarity versus affective value,' Journal of Personality and Social Psychology, 29, 374-380.

Al Ariss, A., Koall, I., Özbilgin, M., \& Suutari, V. (2012), 'Careers of skilled migrants: towards a theoretical and methodological expansion,' Journal of Management Development, 31, 92-101.

Al Ariss, A., \& and Syed, J. (2011), 'Capital Mobilization of Skilled Migrants: A Relational Perspective,’ British Journal of Management, 22, 286-304.

Ashforth, B. and Mael, F. (1989), 'Social identity theory and the organization,' The Academy of Management Review, 14, 1, 20-39.

Aure, M. (2012), 'Highly skilled dependent migrants entering the labour market: Gender and place in skill transfer,' Geoforum, 45, 275-284.

Australian Bureau of Statistics (2001), 2001 Census Tables : Australia 20680-Occupation by Sex - Australia, Canberra.

Aviram, R. B. (2007), ‘Object Relations and Prejudice: from In-group Favoritism to Outgroup Hatred,' International Journal of Applied Psychoanalytic Studies, 4, 4-14.

Aydemir, A., and Skuterud, M. (2004), Explaining the deteriorating entry earnings of Canada’s immigrant cohorts: 1966-2000, Analytical Studies Branch Research Paper Series.

Ball, C., and Haque, A. (2003). 'Diversity in religious practice: implications of Islamic values in the public workplace’. Public Personnel Management, 32, 315-330.

Baruch, Y., \& Holtom, B. (2008), ‘Survey response rate levels and trends in organizational research,' Human Relations, 6, 1139-1160.

Baruch, Y., and Peiperl, M. (2000), ‘The impact of an MBA on graduate careers,' Human Resource Management Journal, 10, 69-90. 
Bauder, H., and Cameron, E. (2002), Cultural barriers to labour market integration: Immigrants from South Asia and the former Yugoslavia, Vancouver: Vancouver Centre of Excellence Research on Immigration and Integration in the Metropolis.

Becker, G. (1971), The Economics of Discrimination (2nd ed.), Chicago: Chicago University Press.

Ben-Ner, A., McCall, B., Stephane, M., and Wang, H. (2006), Identity and Self-Other Differentiation in Work and Giving Behaviors: Experimental Evidence, Industrial Relations Centre (IRC) and Carlton School of Management, University of Minnesota.

Binder, J., Brown, R., Zagefka, H., Holloway, R., Funke, F., Kessler, T., et al. (2009), ‘Does contact reduce prejudice or does prejudice reduce contact? A longitudinal test of the contact hypothesis among majority and minority groups in three European countries,' Journal of Personality and Social Psychology, 96, 843-856.

Birrell, B., Hawthorne, L., and Richardson, S. (2006), Evaluation of the General Skilled Migration Categories, Canberra: Department of Immigration Multicultural Affairs.

Block, F. (1990), Postindustrial Possibilities: A Critique of Economic Discourse, Berkley and Los Angeles: University of California Press.

Blythe, J., Baumann, A., Rhéaume, A., and McIntosh, K. (2009), 'Nurse migration to Canada: pathways and pitfalls of workforce integration,' Journal of Transcultural Nursing, 20, 202-210.

Bowles, S., and Gintis, H. (1975), 'The problem with Human Capital Theory: a Marxian Critique,’ The American Economic Review, 65, 74-82.

Byrne, D. (1971), The Attraction Paradigm, New York: Academic Press.

Caprara, G. V., Vecchione, M., and Barbaranelli, C. (2007), 'When likeness goes with liking: the case of political preference,' Political Psychology, 28, 609-632. 
Carlsson, M., and Rooth, D. (2007), 'Evidence of ethnic discrimination in the Swedish labor market using experimental data,' Labor Economics, 14, 716-729.

Chapman, B., and Iredale, R. (1993), 'Immigrant qualifications: recognition and relative wage outcomes,' International Migration Review, 27, 359-387.

DEEWR. (2013), Skill Shortage List, Australia.

Deprez-Sims, A., and Morris, S. (2010), 'Accents in the workplace: their effects during a job interview,' International Journal of Psychology, 45, 417-426.

Devendorf, S., and Highhouse, S. (2008) 'Applicant-employee similarity and attraction to an employer,' Journal of Occupational and Organizational Psychology, 81, 607-617.

DIC. (2012), Australia’s Migration Trends 2011-12 At A Glance.

DIC. (2013), Australia’s Migration Trends 2011-12.

Dustmann, C., and Fabbri, F. (2003), 'Language proficiency and labour market performance of immigrants in the UK,' The Economic Journal, 113, 489, 695.

Evans, M., and Kelley, J. (1991), ‘Prejudice, discrimination, and the labor market: attainments of immigrants in Australia,' The American Journal of Sociology, 97, 721759.

Greer, T., Chuchinprakarn, N., \& Seshadri, S. (2000), 'Likelihood of Participating in Mail Survey Research: Business Respondents' Perspectives,' Industrial Marketing Management, 29, 97-109.

Ghumman, S., Ryan, A., Barclay, L., and Markel, K. (2013), 'Religious discrimination in the workplace: a review and examination of current and future trends,' Journal of Business and Psychology, 1-16. 
Goldberg, C. (2005) 'Relational demography and similarity-attraction in interview assessments and subsequent offer decisions,' Group and Organization Management, 30, 597-624.

Goldberg, C., Riodan, C., and Schaffer, B. S. (2010), 'Does social identity theory underlie relational demography? A test of the moderating effects of uncertainty reduction and status enhancement on similarity effects,' Human Relations, 63, 903-926.

Groutsis, D. (1998). Immigrant women and the recognition of their qualifications: Case studies of nursing and medical professionals, University of New South Wales, Sydney.

Guest, D., and Conway, N. (2002), 'Communicating the psychological contract: An employer perspective,’ Human Resource Management Journal, 12, 22-38.

Harrisons, D., Price, K., and Bell, M. (1998), 'Beyond relational demography: time and the effects of surface and deep level diversity on work group cohesion,' Academy of Management Journal, 41, 96-107.

Hebbani, A., and Colic-Peisker, V. (2012), ‘Communicating one’s way to employment: a case study of African settlers in Brisbane, Australia,' Journal of Intercultural Studies, 33, 529-547.

Hensley, W. E. (1981), 'The effects of attire, location, and sex on aiding behaviour: a similarity explanation,' Journal of Nonverbal Behavior, 6, 3-11.

Hosoda, M., and Stone-Romero, E. (2010), 'The effects of foreign accents on employmentrelated decisions,' Journal of Managerial Psychology, 25, 113-132.

Kang, M., Sklar, M., and Johnson, K. (2011), 'Men at work: using dress to communicate identities,' Journal of Fashion Marketing and Management, 15, 412-427. 
Kim, S., Wang, Y., Deng, S., Alvarez, R., and Li, J. (2011), 'Accent, perpetual foreigner stereotype, and perceived discrimination as indirect links between English proficiency and depressive symptoms in Chinese American adolescents,' Developmental Psychology, 47, 289-301.

King, E., and Ahmad, A. (2010), ‘An experimental field study of interpersonal discrimination toward Muslim job applicants,' Personnel Psychology, 63, 881-906.

Kostenko, W., Harris, M., and Zhao, X. (2012), 'Occupational transition and country-oforigin effects in the early stage occupational assimilation of immigrants: some evidence from Australia,' Applied Economics, 44, 4019-4035.

Kvanli, A., Pavur, R., and Guynes, S. (2000), Introduction to Business Statistics (5 ed.), Ohio: South-Western College Publishing.

Leigh, A., Booth, A., and Varganova, E. (2009), Does Racial and Ethnic Discrimination Vary Across Minority Groups? Evidence From Three Experiments, Retrieved 17th June, 2009, from http://economics.com.au/?p=3636andcpage=1

Lippi-Green, R. (1997), English with an Accent: Language, Ideology, and Discrimination in the United States, London: Routledge.

Livingstone, D. (1999), 'Beyond Human Capital Theory: the underemployment problem,’ International Journal of Contemporary Sociology, Special Issue on Contemporary Research Trends in Sociology of Education, 36, 163-192.

Markus, A. (2009), Mapping social cohesion:The Scanlon surveys summary report. Melbourne, Victoria: Monash Institute for the Study of Global Movements.

Marsh, H. (1998), 'Pairwise deletion for missing data in structural equation models: nonpositive definite matrices, parameter estimates, goodness of fit, and adjusted sample sizes,' Structural Equation Modeling, 5, 22-36. 
Marx, J. H., and Spray, S. L. (1972), “Birds of a feather’: social-class status and religiocultural value homophily in the mental health field,' Journal of Health and Social Behaviour, 13, 413-428.

McPherson, M., Smith-Lovin, L., and Cook, J. M. (2001), 'Birds of a feather: homophily in social networks,' Annual Review of Sociology, 27, 415-444.

Montoya, M., and Horton, R. (2012), ‘A meta-analytic investigation of the processes underlying the similarity-attraction effect,'. Journal of Social and Personal Relationships, 30, 64-94.

Montoya, M., Horton, R., and Kirchner, J. (2008), 'Is actual similarity necessary for attraction? A meta-analysis of actual and perceived similarity,' Journal of Social and Personal Relationships, 25, 889-922.

Oreopoulos, P. (2011), 'Why do skilled immigrants struggle in the labor market? A Field experiment with thirteen thousand resumes,' American Economic Journal: Economic Policy, 3, 148-171.

Ozbilgin, M and Tatli, A. (2005), ‘Understanding Bourdieu’s Contribution to Organization and Management Studies,' Academy of Management Review 30, 855-877.

Parasnis, J., Fausten, D., and Cheo, R. (2008), 'Do Australian qualifications help? The effect of host country qualification on migrant participation and unemployment,' The Economic Record, 84 (special issue).

Pio, E. (2005), 'Knotted strands: working lives of Indian women migrants in New Zealand,’. Human Relations, 58, 1277-1299.

Productivity Commission Research Report (2006), Economic Impacts of Migration and Population Growth, Productivity Commission. 
Qureshi, K., Varghese, V. J., and Osella, F. (2013), ‘Indian Punjabi skilled migrants in Britain: of brain drain and under-employment,' Journal of Management Development, 32, 182-192.

Rakic, T., Steffans, M., and Mummendey, A. (2011), 'When it matters how you pronounce it: The influence of regional accents on job interview outcome,' British Journal of Psychology, 102, 868-883.

Ramboarison-Lalao, L., Ariss, A. A., and Barth, I. (2012), ‘Careers of skilled migrants: understanding the experiences of Malagasy physicians in France,' Journal of Management Development, 31, 116-129.

Roebken, H. (2010), 'Similarity attracts: an analysis of recruitment decisions in Academia,' Educational Management Administration and Leadership, 38, 472-486.

Rudman, R. (1999), Human Resource Management in New Zealand (3rd ed.), Auckland: Addison Wesley Longman New Zealand Limited.

Sacco, J., Scheu, C., Ryan, A. M., and Schmitt, N. (2003), ‘An investigation of race and sex similarity effects in interviews: A multilevel approach to relational demography,' Journal of Applied Psychology, 88, 852-865.

Schneider, B. (1987), ‘The people make the place,’ Personnel Psychology, 40, 437-453.

Singh, R., and Teoh, J. (1999), 'Attitudes and attraction: a test of two hypotheses for the similarity dissimilarity asymmetry,' British Journal of Social Psychology, 38, 427443.

Somerville, K., and Walsworth, S. (2009), 'Vulnerabilities of highly skilled immigrants in Canada and the United States,' American Review of Canadian Studies, 39, 147-161. 
Trautner, M., and Kwan, S. (2010), 'Gendered appearance norms: an analysis of employment discrimination lawsuits, 1970-2008,' Gender and Sexuality in the Workplace, 20, 127-150.

Wagner, R., and Childs, M. (2006), 'Exclusionary narratives as barriers to the recognition of qualifications, skills and experience: a case of skilled migrants in Australia,' Studies in Continuing Education, 28, 49-62.

Welch, F. (1975), 'The human capital approach: Education, discrimination, and life cycles,' American Economic Association, 65, 63-73. 
Figure 1 Study variables and relationships

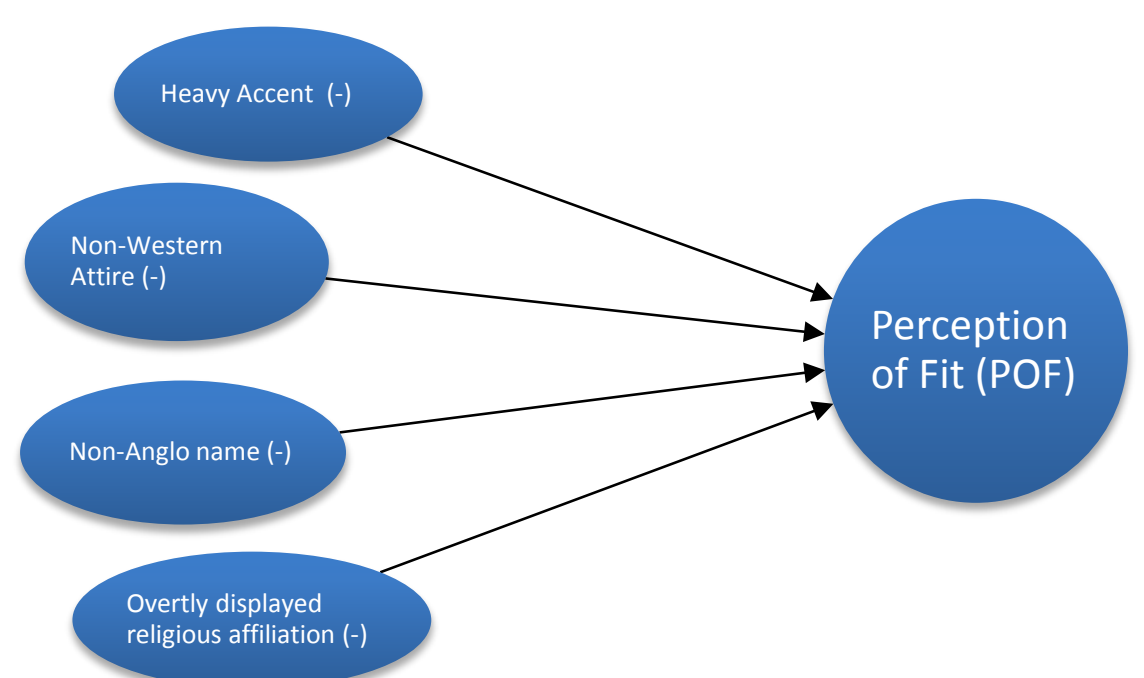

40 
Table 1: Demographic details of sample

\section{Frequency (n) $\quad$ Percent (\%)}

Number of People in Organisation

$1-50$

54

17.8

$51-100$

21

6.9

$101-500$

41

13.5

$500+$

188

61.8

Ethnic Composition of Senior Management

Ethnically Diverse

133

43.8

Anglo/Celtic but non-Australian

31

10.2

Mainly white Australian

129

42.4

Predominantly non-Anglo

11

3.6

Gender Majority of Organisation

Majority Male

Majority Female

14

4.6

Evenly Balanced

68

22.4

Generation Majority of Organisation

Mainly Baby Boomers

Mainly Generation X and Y

82

27.0

Evenly Balanced 
Table 2: Means and Standard Deviations of Key Variables

\begin{tabular}{|c|c|c|}
\hline & \multicolumn{2}{|c|}{ Mean (SD) } \\
\hline Item & $\begin{array}{l}\text { Decision makers who have } \\
\text { worked mainly with } \\
\text { Anglo/Celtic Australians } \\
(\mathrm{n}=36)\end{array}$ & $\begin{array}{l}\text { Decision makers who originate } \\
\text { from immigrant backgrounds or } \\
\text { have ethnically diverse social } \\
\text { networks and are accepting of } \\
\text { immigrant candidates }(\mathrm{n}=128)\end{array}$ \\
\hline Accent & $2.92(.73)^{*}$ & $2.56(.78)^{*}$ \\
\hline Attire & $2.69(.89)^{*}$ & $2.42(.81)^{*}$ \\
\hline Non-Anglo names & $2.56(.84)^{*}$ & $2.17(.85)^{*}$ \\
\hline \multirow[t]{2}{*}{ Religious affiliation } & $2.69(.89)$ & $2.45(.77)$ \\
\hline & $\begin{array}{l}\text { Anglo Australian Clientele } \\
(\mathrm{n}=74)\end{array}$ & $\begin{array}{l}\text { Ethnically Diverse Clientele } \\
(\mathrm{n}=186)\end{array}$ \\
\hline Accent & $2.68(.70)$ & $2.55(.75)$ \\
\hline Attire & $2.80(.79)^{*}$ & $2.28(.81)^{*}$ \\
\hline \multirow[t]{2}{*}{ Non-Anglo names } & $2.42(.86)^{*}$ & $2.08(.78)^{*}$ \\
\hline & $\begin{array}{l}\text { Mostly Ethnically Diverse } \\
\text { Senior Management Team } \\
(\mathrm{n}=118)\end{array}$ & $\begin{array}{l}\text { Mostly White Australian Senior } \\
\text { Management Team }(n=115)\end{array}$ \\
\hline Accent & $2.52(.75)$ & $2.68(.74)$ \\
\hline Attire & $2.37(.80)$ & $2.43(.85)$ \\
\hline Non-Anglo names & $2.06(.77)^{*}$ & $2.30(.85)^{*}$ \\
\hline \multirow[t]{2}{*}{ Religious affiliation } & $2.34(.75)$ & $2.46(.80)$ \\
\hline & Majority Males (n=203) & Even Gender Balance $(n=56)$ \\
\hline Accent & $2.57(.76)$ & $2.69(.73)$ \\
\hline Attire & $2.43(.83)$ & $2.41(.87)$ \\
\hline Non-Anglo names & $2.23(.82)$ & $2.10(.80)$ \\
\hline & & $2.49 \quad .80)$ \\
\hline
\end{tabular}




\begin{tabular}{|l|l|l|}
\hline Religious affiliation & $2.43(.80)$ & \\
\hline & $\begin{array}{l}\text { Decision Makers with Limited } \\
\text { Cultural Understanding (n=118) }\end{array}$ & $\begin{array}{l}\text { Decision Makers with High } \\
\text { Cultural Understanding (n=150) }\end{array}$ \\
\hline Non-Anglo Name & $2.32(.87)^{*}$ & $2.07(.75)^{*}$ \\
Accent & $2.69(.73)$ & $2.50(.75)$ \\
Religion Affiliation & $2.59(.83)^{*}$ & $2.33(.76)^{*}$ \\
Attire & $2.58(.86)^{*}$ & $2.25(.77)^{*}$ \\
\hline
\end{tabular}

*Significant difference between groups as determined by t-tests and Wilcoxon signed rank tests.

Table 3: Mann Whitney U (Wilcoxon Rank Sum) Test Results

\begin{tabular}{|c|c|c|c|}
\hline & & \multicolumn{2}{|c|}{ Mean Rank } \\
\hline Item & $\begin{array}{l}\text { Wilcoxon Rank-Sum } \\
\text { Test Statistics }\end{array}$ & $\begin{array}{l}\text { Decision makers } \\
\text { who have worked } \\
\text { mainly with } \\
\text { Anglo/Celtic } \\
\text { Australians }\end{array}$ & $\begin{array}{l}\text { Decision makers who } \\
\text { originate from } \\
\text { immigrant } \\
\text { backgrounds or have } \\
\text { ethnically diverse } \\
\text { social networks and } \\
\text { are accepting of } \\
\text { immigrant candidates }\end{array}$ \\
\hline $\begin{array}{l}\text { Non-Anglo names } \\
\text { Accent } \\
\text { Attire } \\
\text { Suitability of PEM }\end{array}$ & $\begin{array}{l}U=2067, Z=-2.13, \\
p=.033 \\
U=1901.5, Z=-2.86, \\
p=.004 \\
U=1878, Z=-2.92, \\
p=.004 \\
U=2352, Z=-2.48, \\
p=.013\end{array}$ & $\begin{array}{l}103.11 \\
104.46 \\
108.08 \\
113.52\end{array}$ & $\begin{array}{l}84.48 \\
83.28 \\
83.11 \\
90.39\end{array}$ \\
\hline & & $\begin{array}{l}\text { Anglo Australian } \\
\text { Clientele }\end{array}$ & $\begin{array}{l}\text { Ethnically Diverse } \\
\text { Clientele }\end{array}$ \\
\hline Attire & $\mathrm{U}=4843.5, \mathrm{z}=-4.579$ & 166.77 & 121.73 \\
\hline
\end{tabular}




\begin{tabular}{|c|c|c|c|}
\hline \multirow[t]{2}{*}{ Eye contact } & $\begin{array}{l}p=.000 \\
U=5659.5, z=-3.180 \\
p=.001 \\
U=5849, z=-2.973 \\
p=.003\end{array}$ & $\begin{array}{l}156.03 \\
152.54\end{array}$ & $\begin{array}{l}125.98 \\
126.62\end{array}$ \\
\hline & & $\begin{array}{l}\text { Mostly Ethnically } \\
\text { Diverse Senior } \\
\text { Management Team }\end{array}$ & $\begin{array}{l}\text { Mostly White } \\
\text { Australian Senior } \\
\text { Management Team }\end{array}$ \\
\hline \multirow[t]{2}{*}{$\begin{array}{l}\text { Ethnic composition } \\
\text { of senior } \\
\text { management }\end{array}$} & $\begin{array}{l}U=6303, Z=-2.19 \\
p=.029\end{array}$ & 124 & 119 \\
\hline & & $\begin{array}{l}\text { Decision Makers } \\
\text { with Low Cultural } \\
\text { Understanding }\end{array}$ & $\begin{array}{l}\text { Decision Makers with } \\
\text { High Cultural } \\
\text { Understanding }\end{array}$ \\
\hline \multirow[t]{2}{*}{$\begin{array}{l}\text { Non-Anglo names } \\
\text { Religious } \\
\text { affiliations } \\
\text { Attire }\end{array}$} & $\begin{array}{l}U=8133, Z=-2.72, \\
p=.007 \\
U=8282, Z=-2.24, \\
p=.025 \\
U=7729.5, Z=-3.25, \\
p=.001\end{array}$ & $\begin{array}{l}154.91 \\
151.71 \\
158.17\end{array}$ & $\begin{array}{r}130.97 \\
131.59 \\
128.42\end{array}$ \\
\hline & & $\begin{array}{l}\text { Anglo Australian } \\
\text { Clientele }\end{array}$ & $\begin{array}{l}\text { Ethnically Diverse } \\
\text { Clientele }\end{array}$ \\
\hline $\begin{array}{l}\text { Attire } \\
\text { Non-Anglo Name } \\
\text { Eye Contact }\end{array}$ & $\begin{array}{l}U=5659.50, Z=-3.18, \\
p=.001 \\
U=5849, Z=-2.97, \\
p=.003 \\
U=4843.50, Z=-4.58, \\
p=.000\end{array}$ & $\begin{array}{r}166.77 \\
156.03 \\
152.54\end{array}$ & $\begin{array}{r}121.73 \\
125.98 \\
126.62\end{array}$ \\
\hline
\end{tabular}


Table 4: Between group comparisons for concerns for suitability of ethnic groups

\begin{tabular}{|l|l|l|l|}
\hline & & \multicolumn{2}{|c|}{ Mean Rank } \\
\hline Ethnic group & Mann-Whitney U statistic & $\begin{array}{l}\text { White Australian } \\
(\mathrm{n}=128)\end{array}$ & $\begin{array}{l}\text { Ethnically Diverse } \\
(\mathrm{n}=133)\end{array}$ \\
\hline South East Asian & $\mathrm{U}=7067.50, \mathrm{Z}=-2.62, \mathrm{p}=.009$ & 142.29 & 120.14 \\
\hline Indian & $\mathrm{U}=7342.50, \mathrm{z}=-2.09, \mathrm{p}=.036$ & 138.93 & 123.37 \\
\hline Chinese & $\mathrm{U}=7325, \mathrm{z}=-2.15, \mathrm{p}=.032$ & 140.27 & 122.08 \\
\hline
\end{tabular}

Aviram, R. B. (2007). Object Relations and Prejudice: From In-group Favoritism to Outgroup Hatred. International Journal of Applied Psychoanalytic Studies, 4(1), 4-14.

Becker, G. (1971). The Economics of Discrimination (2nd ed.). Chicago: Chicago University Press.

Block, F. (1990). Postindustrial possibilities: A critique of economic discourse. Berkley and Los Angeles: University of California Press.

Cameron, R. (2011). Responding to Australia's Regional Skill Shortages Through Regional Skilled Migration. Journal of Economic and Social Policy, 14(3).

Chaloff, J., \& Lemaitre, G. (2009). Managing highly-skilled labour migration: a comparative analysis of Migration policies and challenges in OECD countries. OECD social, employment and migration working papers. Directorate for employment, labour and social affairs,. Paris. Retrieved from http://www.oecd.org/els/mig/46656535.pdf

Chang, M., Astin, A., \& Kim, D. (2004). Cross-racial interaction among undergraduates: Some consequences, causes, and patterns. Research in Higher Education, 45, 529553.

Department of Education Employment and Workplace Relations (DEEWR). (2012). Skill Shortage List, Australia Retrieved 8 July, 2013, from http://foi.deewr.gov.au/system/files/doc/other/ausskillshortagelistdec2012.pdf

DIC. (2012). Australia’s Migration Trends 2011-12 At A Glance.

DIC. (2013). Australia’s Migration Trends 2011-12.

Evans, M., \& Kelley, J. (1991). Prejudice, Discrimination, and the Labor Market: Attainments of Immigrants in Australia. The American Journal of Sociology, 97(3), 721-759.

Hawthorne, L. (2011). Competing for skills: Migration policies and trends in New Zealand and Australia. Wellington: International Migration Settlement and Employment 
Dynamics Retrieved from

http://www.immi.gov.au/media/publications/research/_pdf/migration-policies-trendsfullreport.pdf.

Kostenko, W., Harris, M., \& Zhao, X. (2012). Occupational transition and country-of-origin effects in the early stage occupational assimilation of immigrants: some evidence from Australia. Applied Economics, 44, 4019-4035.

Livingstone, D. (1999). Beyond Human Capital Theory: The Underemployment Problem. International Journal of Contemporary Sociology, 36 Special Issue on Contemporary Research Trends in Sociology of Education(2), 163-192.

McLaren, L. (2003). Anti-Immigrant Prejudice in Europe: Contact, Threat Perception, and Preferences for the Exclusion of Migrants. Social Forces, 81(3), 909-936.

Pettigrew, T., \& Tropp, L. (2006). A meta-analytic test of intergroup contact theory. Journal of Personality and Social Psychology, 90(5), 751-783.

Smith, R. (2011). Migration and the innovation agenda. Science and Research Working Paper 2011-02. Industry Policy and Economic Analysis Branch, Department of Innovation, Industry, Science and Research

Canberra.

Welch, F. (1975). The human capital approach: An appraisal. Human capital theory: Education, discrimination, and life cycles. American Economic Association, 65(2), 63-73. 